ations) this human 'island' supported a fauna of 53 clones. Most were transient, and appeared on only one sampling occasion but one persisted for several months and two others occurred for most of the period of observation.

The $E$. coli clones therefore showed considerable 'species' turnover although the actual number of clones remained fairly constant. New clones probably arrived by immigration from the food as the nearby islands in the Levin Archipelago (the two Doctors Levin, their children and their cat) shared a similar array of clones. Clones were lost by random extinction. These observations further support the view that the species composition of islands involves considerable flux.

\section{Biogeography and disease}

Other useful analogies may be drawn between the biology of island birds and that of human pathogens. For example, islands - such as the Galapagos - are uniquely favourable in promoting the origin of new bird species. It is possible that the evolution of new pathogens takes place primarily in highly sub-divided human populations and that the recent expansion of mankind to form a single large continental mass with free interchange among its parts has greatly retarded the evolution of new disease organisms.

Birds on isolated islands with few competing species and slow species turnover have habitat preferences quite different from mainland populations ${ }^{2}$. The ecology of pathogens in isolated human populations might also differ from that in modern cities.

After defaunation by volcanic explosions or poison gas, islands show changes in the diversity, turnover and ecology of their inhabitants ${ }^{17,18}$; the return to equilibrium may be long delayed. Recolonization of a human host after antibiotic treatment could lead to similar and unexpected changes in the ecology of the pathogens which remain.

The most recent models of island biogeography use differences in the efficiency of migration and resource utilization of individual species to predict the species composition of birds on islands ${ }^{19}$. Clones of $E$. coli also differ greatly from each other in their ability to utilize resources ${ }^{20}$. Developments in theories of island biogeography may therefore help to explain why some clones are resident and some transient in the intestine ${ }^{14}$, and why certain pathogens (such as hepatitis B or herpes virus) are present in all human populations including those on islands - while others occur only sporadically ${ }^{8}$. It is even possible that such developments may help to eliminate pathogens by means of the secular miracles of medicine rather than the direct intervention of a saint.

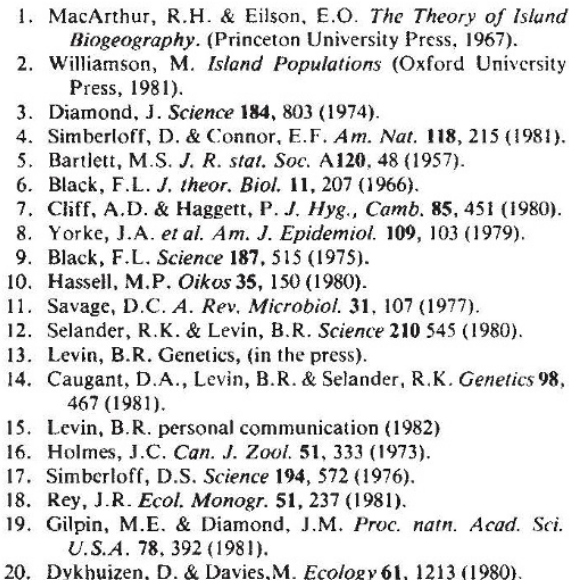

1. MacArthur, R.H. \& Eilson, E.O. The Theory of Islund Biogeography. (Princeton University Press, 1967).

Bllamson, M. Islandations (Oxford University

. Yorke, J.A et al Am. J. Epidemiol

3. Levin, B.R. Genetics, (in the press)

U.S.A. 78, 392 (1981).
Dykhuizen, D. \& Davies,M. Ecology 61, 1213 (1980)

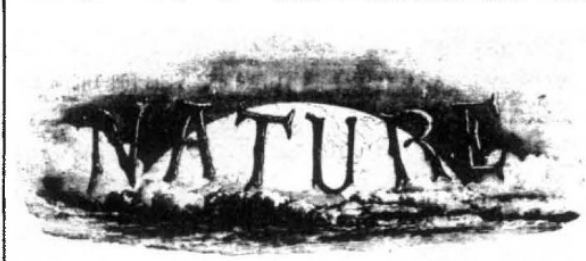

100 YEARS AGO

\section{ON THE CONSERVATION OF SOLAR ENERGY ${ }^{1}$}

The question of the maintenance of Solar Energy is one that has been looked upon with deep interest by astronomers and physicists from the time of La Place downwards.

The amount of heat radiated from the sun has been approximately computed by the aid of the pyrheliometer of Pouillet and by the actinometers of Herschel and others at $18,000,000$ of heat units from every square foot of its surface per hour, or, put popularly, as equal to the heat that would be produced by the perfect combustion every thirty-six hours of a mass of coal of specific gravity $=1.5$ as great as that of our earth.

If the sun were surrounded by a solid sphere of a radius equal to the mean distance of the sun from the earth $(95,000,000$ of miles), the whole of this prodigious amount of heat would be intercepted: but considering that the earth's apparent diameter as seen from the sun is only seventeen seconds, the earth can intercept only the 2,250-millionth part. Assuming that the other planetary bodies swell the amount of intercepted heat by ten times this amount, there remains the important fact that 24999999

$\frac{24999999}{225000000}$ of the solar energy is radiated into

1 P

Paper read at the Royal Society, March 2, by C. William Siemens, D.C.L., L.L.D., F.R.S., Mem. Inst. C.E. space, and apparently lost to the solar system, and only $\frac{1}{225000000}$ utilised.

Notwithstanding this enormous loss of heat, solar temperature has not diminished sensibly for centuries, if we neglect the periodic changes, apparently connected with the appearance of sun-spots that have been observed by Lockyer and others, and the question forces itself upon us how this great loss can be sustained without producing an observable diminution of solar temperature even within a human lifetime.

Amongst the ingenious hypotheses intended to account for a continuance of solar heat is that of shrinkage, or gradual reduction of the sun's volume suggested by Helmholtz. It may, however, be urged against this theory that the heat so produced would be liberated throughout its mass; and would have to be brought to the surface by conduction, aided perhaps by convection; but we know of no material of sufficient conductivity to transmit anything approaching the amount of heat lost by radiation.

Chemical action between the constituent parts of the sun has also been suggested; but here again we are met by the difficulty that the products of such combination would ere this have accumulated on the surface, and would have formed a barrier against further action.

These difficulties have led Sir Wm. Thomson, following up Mayer's speculation, to the suggestion that the cause of the maintenance of solar temperature might be found in the circumstance of meteorolites falling upon the sun from great distances in space, or with an acquired velocity due to such fall, and he shows that each pound of matter so imported would represent a large number of heat units depending upon the original distance. Yet the aggregate of material that would thus have to be incorporated with the sun would tend to disturb the planetary equilibrium, and must ere this have shortened our year to an extent exceeding that resulting from astronomical records and observation. In fact, Sir William Thomson soon abandoned the meteoric hypothesis for that of simple transfer of heat from the interior of a liquid sun to the surface by means of convection currents, which latter hypothesis appears at the present time to be supported by Prof. Stokes and other leading physicists of the day.

But if either of these hypotheses could be proved we should only have the satisfaction of knowing that the solar waste of energy by dissipation into space was not dependent entirely upon loss of its sensible heat, but that its existence as a luminary would be prolonged by calling into requisition a limited, though may be large, store of energy in the form of separated matter. The true solution of the problem will be furnished by a theory, according to which the radiant energy which is now supposed to be dissipated into space and irrecoverably lost to our solar system, could be arrested and brought back in another form to the sun itself, there to continue the work of solar radiation.

CAN Mr Wallace throw any light on $\mathrm{Mr}$ Allen's somewhat extraordinary sentence: "I feel a genuine respect for every donkey I meet, when I remember that it was the mere accidental possession of an opposable thumb that gave my ancestors a start over his in the race for the inheritance of the earth towards the very close of the tertiary period."'I take $\mathrm{Mr}$ Allen to be an evolutionist, but there is no place for accident in evolution, or in any other scientific theory. The "opposable thumb" must be the result of some conditioning factor, and this being so the word accident is quite out of place.

From Nature 25, 440; March 9, 1882. 